\title{
НЕКОТОРЫЕ ПОЛОЖЕНИЯ ЭКОНОМИЧЕСКОГО УПРАВЛЕНИЯ УСТОЙЧИВЫМ РАЗВИТИЕМ ПРОМЫШЛЕННЫХ ПРЕДПРИЯТИЙ В УСЛОВИЯХ РЕИНДУСТРИАЛИЗАЦИИ
}

\author{
(c) 2019 Смирнова Елена Викторовна \\ доктор экономических наук, профессор \\ Оренбургский государственный университет, Россия, Оренбург \\ E-mail: uadsev@mail.ru \\ (c) 2019 Тычинина Наталья Александровна \\ кандидат экономических наук \\ Оренбургский государственный университет, Россия, Оренбург \\ E-mail: tychinina_nataly@mail.ru \\ (C) 2019 Цыганова Ирина Юрьевна \\ кандидат экономических наук, доцент \\ Оренбургский государственный университет, Россия, Оренбург \\ E-mail: iren23_83@mail.ru \\ (c) 2019 Федорищева Ольга Васильевна \\ кандидат экономических наук, доцент \\ Оренбургский государственный университет, Россия, Оренбург \\ E-mail: owa2010@rambler.ru
}

Решение вопросов экономического управления устойчивым развитием промышленных предприятий приобретают особое значение для современного бизнес-сообщества. В процессе реиндустриализации происходит трансформация условий хозяйствования промышленных предприятий, связанных с изменениями индустриально-технологической основы экономической системы и механизма экономического управления в контексте создания гибких систем управления бизнесом. Реализация концепции устойчивого развития промышленных предприятий на основе экономического управления становится «платформой» укрепления их деловой репутации, роста конкурентоспособности и рыночной капитализации. В статье раскрываются некоторые теоретические и методические положения экономического управления устойчивым развитием российских промышленных предприятий в условиях изменения вектора развития национальной и мировой экономики. Выявлено, что экономическое управление устойчивым развитием играет решающую роль в эффективном функционировании промышленных предприятий и индустриального сектора российской экономики в целом.

Ключевые слова: устойчивое развитие, концепция устойчивого развития, реиндустриализация, экономическое управление, промышленные предприятия, индустриальный сектор.

Принятие в 2014 г. ФЗ № 488 «О промышленной политике» привело к трансформации экономических принципов деятельности российских промышленных предприятий, важнейшее направление которой по признанию топ-менеджмента большинства из них - переориентация управления от цели «максимизация прибыли» / «минимизация издержек» к поддержанию устойчивого развития на базе прироста рыночной стоимости (капитализации), основанной на нематериальных активах или опережающих инновациях.

Активное использование экспортно-сырье- вой базы России препятствует продвижению инновационных секторов экономики, но в тоже время без развития традиционных отраслей промышленности невозможно осуществление полноценных инвестиций в новые высокотехнологичные производства [1].

Изменения, в которых экстренно нуждается отечественная промышленность, связаны с необходимостью новой индустриализации, обеспечивающей ее устойчивое развитие на основе технологического прорыва, что возможно только при темпах прироста ВВП 4-5\%. При этом Банк России и Министерство финансов РФ 
в ближайшей перспективе прогнозируют темпы прироста ВВП на уровне только 1,5-2,0\%.

Кризисные явления в российской экономике заставляют руководство промышленных предприятий искать новые возможности на основе реализации концепции устойчивого развития, что обусловлено необходимостью принятия инвестиционных решений с учетом не только их экономических, но и социальных и экологических последствий [2].

Наряду с необходимостью формирования и поддержания имиджа надежного партнера, реализующего концепцию устойчивого развития, можно выделить и другие важные причины того, чтобы деятельность предприятия была согласована с принципами устойчивости согласно Концепции перехода РФ к устойчивому развитию [3]: 1) рост цен на ресурсы; 2) обеспечение «прозрачности» деятельности для всех заинтересованных сторон (стейкхолдеров); 3) снижение репутационных рисков, связанных с вопросами экологии и безопасности.

С целью обеспечения возможности участия в глобальной конкуренции на рынках товаров, капитала и информации в условиях многолетней стагнации и необходимости инновационного обновления национальной промышленности во всех её секторах особую актуальность приобретает соответствие по стоимости и качеству составляющих её ресурсной базы и прорывными технологиями нового технологического уклада.

Основной акцент в концепции устойчивого развития промышленных предприятий делается на обеспечение долгосрочных условий стабильности их функционирования, что особенно важно в процессе перевода экономики на «промышленные рельсы», сопровождаемым совершенствованием средств производства, расширением основных фондов, механизацией и автоматизацией технических систем [4].

Устойчивое развитие промышленных предприятий в условиях реиндустриализации предполагает реализацию экономического управления ими через улучшение качества принимаемых управленческих решений и их эффективную реализацию путем преодоления сложности проблемных ситуаций, обусловленных большим количеством взаимодействующих факторов и причинно-следственных связей, что может существенно облегчить деятельность менеджеров и обеспечить результативность их работы.

Экономическое управление - один из видов управления в зависимости от объекта и методов, используемых в управлении. Именно экономическое управление предприятием позволяет менеджменту обосновывать и принимать эффективные управленческие решения на основе предварительно выполненного анализа и планово-экономических расчетов [5].

Базовая модель экономического управления устойчивым развитием промышленных предприятий в условиях реиндустриализации представлена на рисунке 1.

Под экономическим управлением устойчивым развитием промышленных предприятий в условиях реиндустриализации будем понимать целенаправленное воздействие на управляемый объект (состояние устойчивости) со стороны субъекта управления (руководство предприятия): 1) посредством комплекса целеориентированных средств воздействия и технологий, объединенных в единую систему экономического управления и обеспечивающих реализацию его функций; 2) позволяющее достичь более высокого качественного состояния посредством количественных и качественных изменений (преобразований), характеризующихся закономерностью, цикличностью, единством, направленностью, необратимостью, альтернативностью и многовариантностью, внутренней противоречивостью, взаимосвязью прогресса и регресса; 3) в условиях объективной необходимости восстановления и развития отечественной промышленности на основе прогрессивных технологий пятого (с элементами шестого) технологического уклада.

Теоретические и методические положения экономического управления устойчивым развитием промышленных предприятий характеризуют стратегическую направленность российской индустриальной трансформации, связанной с реализацией процессов инноватизации и социализации экономики.

Первое положение. Устойчивое развитие экономики определяет совокупность экономических отношений, возникающих по ходу достижения целей развития в процессе финансово-хозяйственной деятельности на всех уровнях управления: первый уровень - предприятия; второй уровень - отрасли; третий уровень - регионы; четвертый уровень - федеральные округа и пятый уровень - национальная экономика. Каждый последующий уровень складывается под влиянием предшествующих состояний устойчивого развития экономики. 


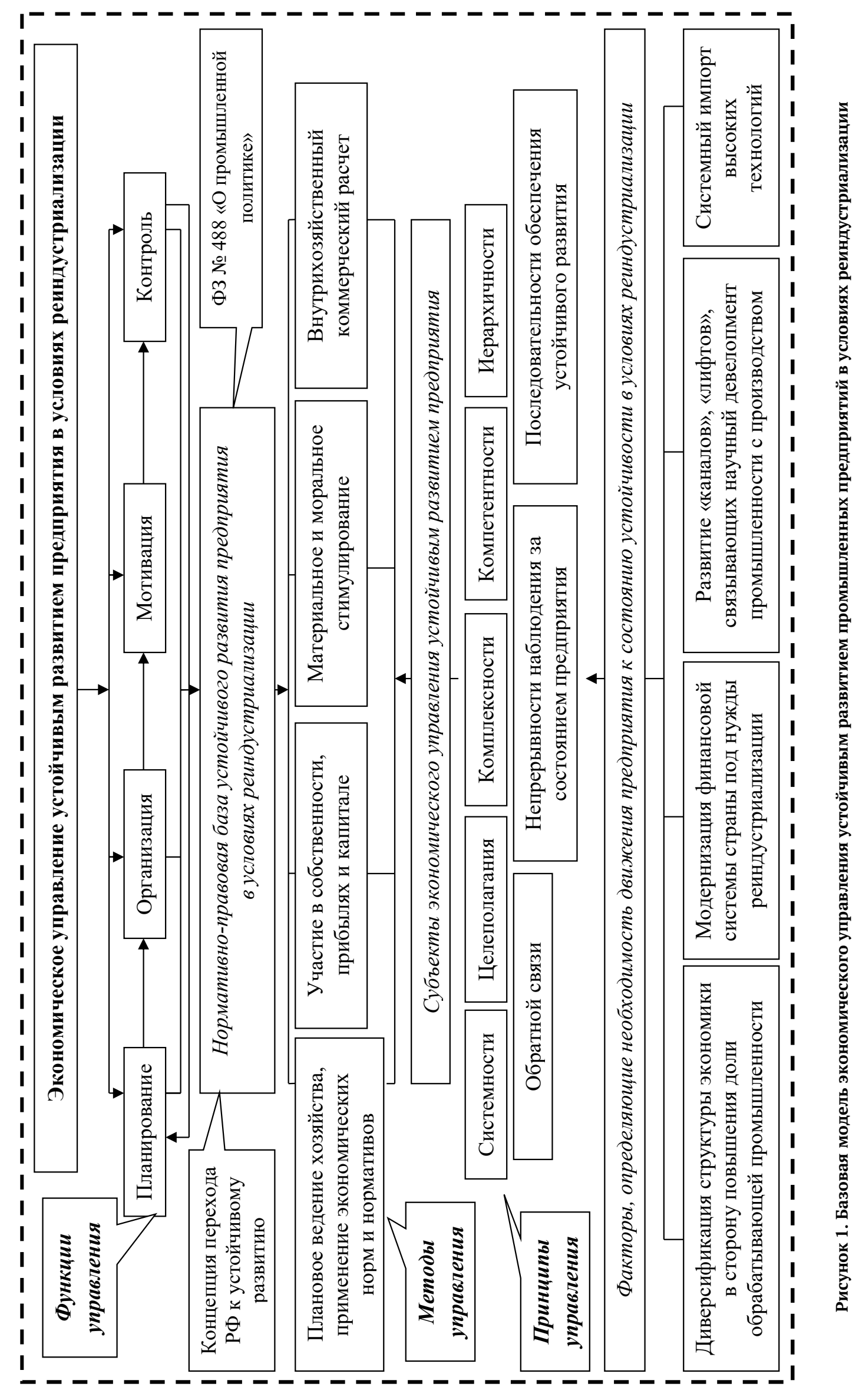


Следовательно, для достижения устойчивого развития экономики следует обеспечить устойчивость моментального состояния предприятия в каждой точке с течением времени.

Второе положение. Устойчивое развитие определяется рядом состояний, характеризующих его отдельные фазы. Фаза развития - одно из качественно различных состояний развивающейся экономической системы [6]. А интеграция двух различных по содержанию понятий «устойчивость» как статика и «развитие» как динамика позволит более полно охарактеризовать устойчивое развитие промышленного предприятия с позиции пространственной ориентации в рамках стабилизации устойчивости и направленности развития.

В связи с этим актуальным представляется выделение зон, содержание которых позволит охарактеризовать состояние предприятия и подобрать адекватный ему инструментарий экономического управления в условиях реиндустриализации:

1. «Зона успеха» - активное использование технологий и продуктов нового технологического уклада, обеспечивающих высокую степень устойчивости развития предприятия, в основе которого сильные конкурентные преимущества.

2. «Потенциал развития» - предприятие применяет отдельные элементы инноваций нового технологического уклада, что даёт возмож- ность в перспективе занять сильные конкурентные позиции.

3. «Устойчивый рост» - предприятие, динамично развиваясь, обладает оптимальной устойчивостью за счёт применения технологий и продуктов доминирующего технологического уклада непрерывно модернизируя и модифицируя их. Экономическое управление предприятием недостаточно эффективно, так как не использован потенциал активного развития.

4. «Предел успешности» - предприятие функционирует в рамках имеющегося производственного потенциала и не развивается. Направляет все усилия на обеспечение роста.

В каждой из этих зон предприятию свойственны определенные подходы к организации экономического управления. При переходе из одной зоны в другую проявляются кризисы управления, которые требуют пересмотра подходов к построению системы экономического управления и зачастую приводят к серьезной реорганизации на предприятии.

На практике, имея такую информацию, руководству нужно оценить, в какой зоне находится предприятие в настоящий момент, сможет ли оно и дальше развиваться в рамках принятого управленческого подхода или ожидаемый кризис перехода потребует более глубокой реформы управления. Для этого разработана двухмерная матрица «Устойчивость-развитие» (рисунок 2).

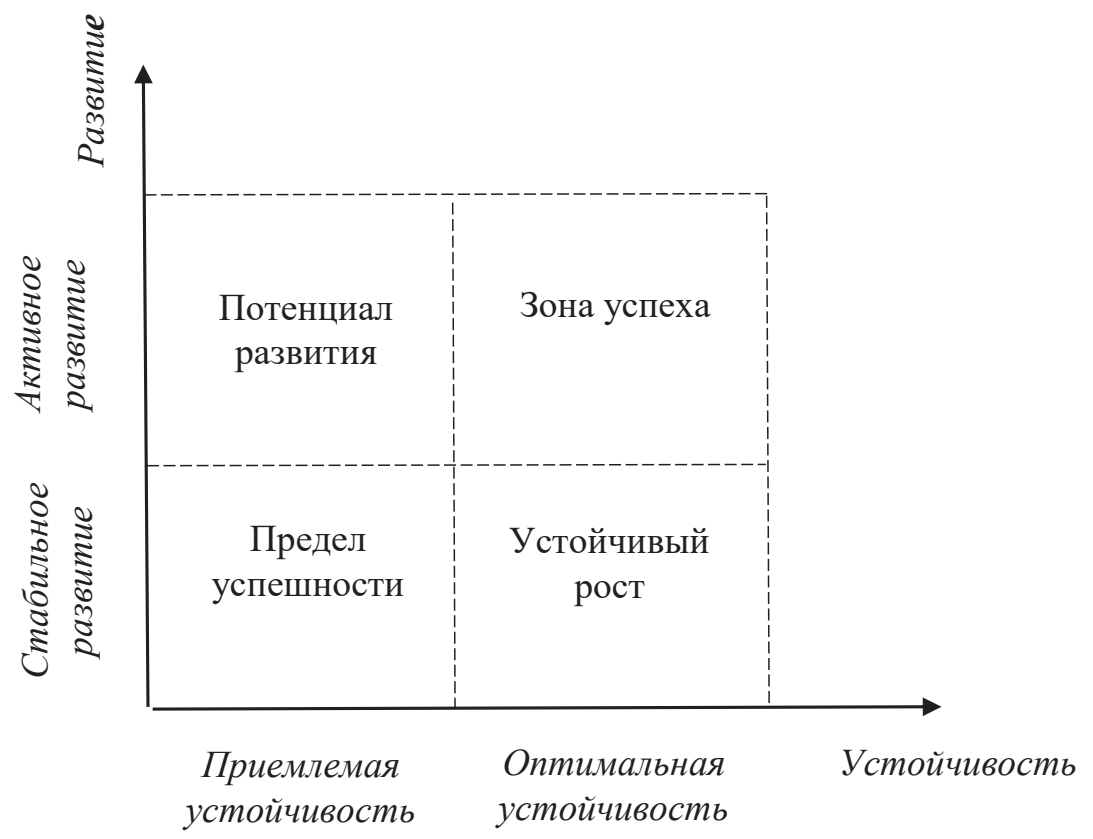

Рисунок 2. Позиционная двухмерная матрица «Устойчивость - развитие» 
Третье положение. На основе анализа стратегии развития предприятия, возможности радикальных преобразований (продажи бизнеса, реструктуризации, смены технологии, линейки продуктов, перехода к новой модели бизнеса, выхода на принципиально новые рынки и т.п.), степени стабильности отрасли и макроокружения, определяется одна из следующих стратегических ситуаций:

1. «Революция» - ситуация радикальных преобразований на предприятии.

2. «Устойчивая область бизнес-процессов»ситуация, в которой можно выделить некоторую область операционных процессов, устойчивую в стратегическом плане.

3. «Устойчивый бизнес»- ситуация, в которой предприятие является устойчивым.

Комплексный анализ фаз и зон развития промышленного предприятия позволит не только оценить существующую систему экономического управления с точки зрения границ применимости управленческих технологий, но и даст возможность прогнозировать кризисы управления, требующие принципиальной смены управленческих подходов. Понимание стратегической ситуации и идентификация типа развития позволит определить стратегически устойчивую область бизнеса, совершенствованием экономического управления которой имеет смысл заниматься, а также даст возможность предвидеть радикальные изменения бизнеса и отдельных его составляющих при смене продуктов и технологий нового технологического уклада.
Виды развития промышленного предприятия, определяющие его тип, представлены на рисунке 3.

Четвертое положение. Устойчивое экономическое развитие промышленных предприятий определяется множеством факторов. Исследование факторов позволяет выявить причины экономических, производственных процессов, а их анализ выявляет внутренние и внешние резервы, которые обеспечивают высокий уровень развития. Существует необходимость в выявлении и систематизации факторов, влияющих на устойчивое экономическое развитие предприятия. Форма и содержание устойчивого развития определяются тем, какие новые комбинации факторов возникают, и как они воздействуют на предприятие.

Пятое положение. Выделяются следующие направления устойчивого развития промышленных предприятий:

1. Рост конкурентоспособности - главное направление развития, так как неконкурентоспособные предприятия становятся банкротами.

2. Рост доходности инвестируемого капитала - важный критерий, который отражает возможность предприятия привлекать инвесторов и кредиты, проводить политику стратегического инвестирования обновления техники и технологий.

3. Развитие производственного потенциала промышленного предприятия - предусматривает технологические инновации, включает развитие персонала и человеческого капитала,

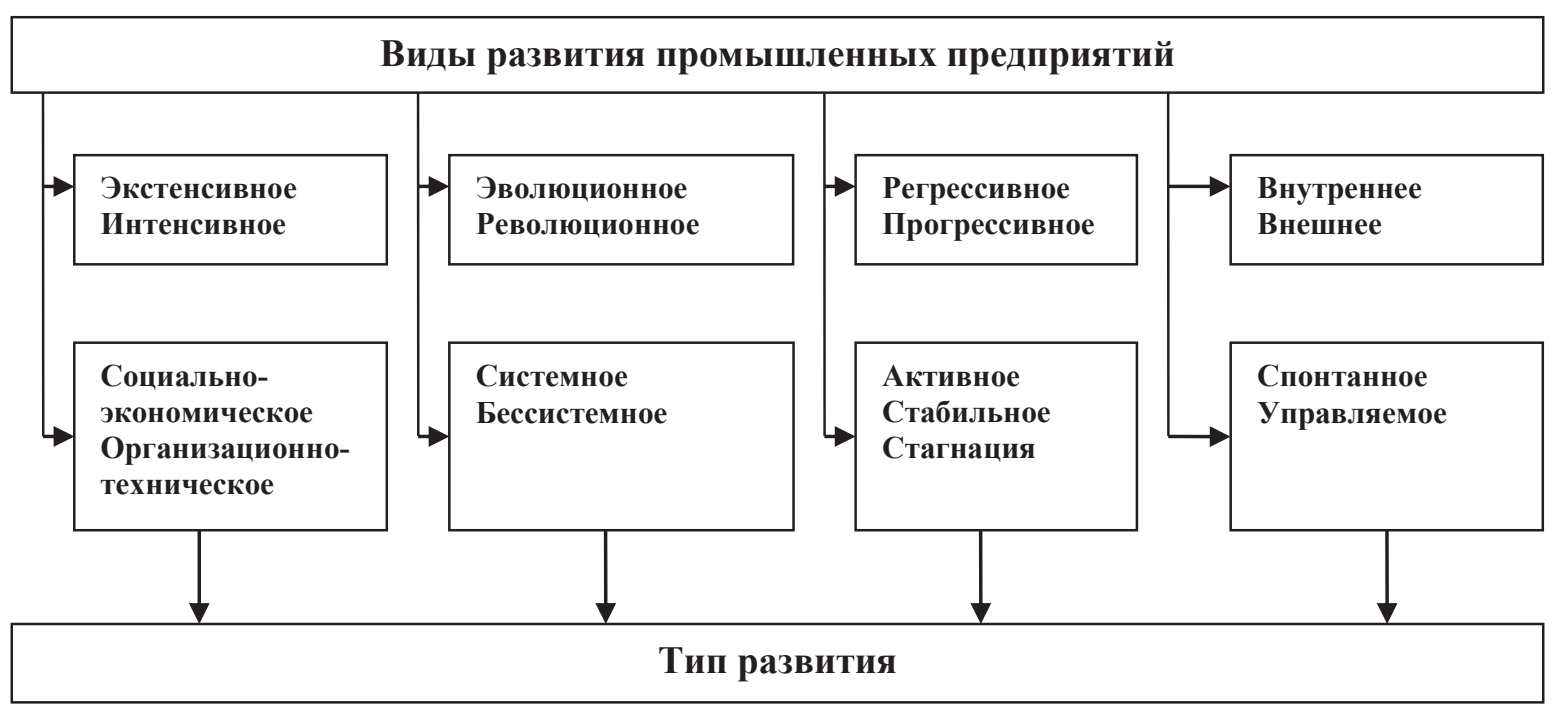

Рисунок 3. Виды развития промышленных предприятий 
интеллектуальные технологии, банки и базы данных, рост финансового и инвестиционного потенциалов.

Шестое положение. В нестабильной экономической среде устойчивое развитие предприятия зависит не только от умения руководства пользоваться всеми рычагами власти, но и умения выстроить постоянно действующий механизм экономического управления, ориентируясь на ресурсы и потенциальные возможности будущего развития предприятия.

Для его эффективной реализации должны быть созданы или трансформированы управленческие институты, способные обеспечить использование новейших тенденций совершенствования техники, технологий, систем управления, и тем самым достичь стабильной прибыльности, максимизации чистых выгод и нормальных условий для расширенного воспроизводства и устойчивого экономического роста в длительной перспективе.

Седьмое положение. Реализация каждой из функций экономического управления устойчивым развитием предприятия предполагает использование соответствующего ей инструментария. В механизме экономического управления устойчивым развитием предприятия, в качестве основных выделим плановую, организационную, мотивационную и контрольную функциональные подсистемы.

Алгоритм как элемент методики оценки эффективности экономического управления устойчивым развитием предприятия через реализацию соответствующего механизма приведен на рисунке 4.

На основе информации, подготовленной

1. Оценка эффективности плановой подсистемы механизма экономического управления

$\checkmark$

2. Построение агрегированного показателя эффективности плановой подсистемы

3. Оценка эффективности организационной подсистемы механизма экономического управления $+$

4. Построение агрегированного показателя эффективности организационной подсистемы

5. Оценка эффективности мотивационной подсистемы механизма экономического управления $+$

6. Построение агрегированного показателя эффективности мотивационной подсистемы $\checkmark$

7. Оценка эффективности контрольной подсистемы экономического управления

\section{$\checkmark$}

8. Построение агрегированного показателя эффективности контрольной подсистемы

9. Построение интегрального показателя эффективности механизма экономического управления и оценки риска

Рисунок 4. Алгоритм оценки эффективности экономического управления устойчивым развитием промышленных предприятий 
на этапах 1, 3, 5 и 7 алгоритма, рассчитываются четыре агрегированных показателя в разрезе функциональных подсистем механизма экономического управления.

Методика может использоваться многократно, причем как на этапе разработки механизма экономического управления предприятием, так и на этапе его реализации. Применяемый в ней подход даст возможность определить «узкие места» в цикле экономического управления.

Восьмое положение. Эффективность экономического управления устойчивым развитием предприятия во многом предопределяется способностью руководства принимать оптимальные решения, а для этого ему необходима эффективная информационная основа.

В современном мире отчетность об устойчивом развитии приобретает все большее репутационное значение, характеризуя уровень корпоративной культуры, социальной ответственности и общественной значимости, адекватности системы экономического управления требованиям времени. Объективность, полнота и прозрачность такой отчетности существенно повышают степень инвестиционной привлекательности предприятий, лояльность их персонала и доверие к ним в деловом сообществе.

По состоянию на 11.04.2019 г. в Националь- ном регистре корпоративных нефинансовых отчетов, который ведет Российский союз промышленников и предпринимателей, было зарегистрировано 924 отчета, опубликованных 176 организациями, начиная с 2000 г. В их числе экологические отчеты (ЭО) - 81, социальные отчеты (CO) - 326, отчеты в области устойчивого развития (ОУР) - 314, интегрированные отчеты (ИО) - 176, отраслевые отчеты - 27.

Девятое положение. Охват показателей отчетности в области устойчивого развития для оценки эффективности экономического управления устойчивым развитием промышленных предприятий в условиях реиндустриализации должен быть достаточен для реального отражения финансово-экономического состояния предприятия, а также разработки эффективных управленческих решений (Таблица 1).

Динамика этих показателей позволяет оценить финансовое взаимодействие предприятия со стейкхолдерами и проанализировать масштаб и структуру финансовых потоков, возникающих в результате распределения созданной экономической стоимости.

Как представляется в условиях реиндустриализации меняется также подход к целеполаганию деятельности промышленных предприятий - от роста прибыли и рентабельности к

Таблица 1. Рекомендуемые ключевые показатели оценки эффективности экономического управления устойчивым развитием промышленных предприятий в условиях реиндустриализации

\begin{tabular}{|c|c|}
\hline Показатель & $\begin{array}{c}\text { Содержание и обоснование выбора показателя/ } \\
\text { Источник получения данных }\end{array}$ \\
\hline Выручка & $\begin{array}{l}\text { Отражает величину дохода предприятия от реализации } \\
\text { основного вида деятельности. Отчет о финансовых ре- } \\
\text { зультатах в составе бухгалтерской (финансовой) отчет- } \\
\text { ности }\end{array}$ \\
\hline $\begin{array}{l}\text { Прибыль до уплаты процентов, налогов и начис- } \\
\text { ления амортизации (EBITDA) }\end{array}$ & $\begin{array}{l}\text { Расчет основан на данных отчетности US GAAP, исполь- } \\
\text { зуется для анализа финансового положения и оценки } \\
\text { стоимости предприятия }\end{array}$ \\
\hline $\begin{array}{l}\text { Рентабельность продаж (маржа прибыли до } \\
\text { уплаты процентов, налогов и начисления аморти- } \\
\text { зации) }\end{array}$ & $\begin{array}{l}\text { Характеризует удельный вес прибыли (EBITDA) в соста- } \\
\text { ве выручки; называют также «нормой прибыльности» }\end{array}$ \\
\hline Финансовый леверидж & $\begin{array}{l}\text { Отражает уровень финансового риска или риска потери } \\
\text { финансовой устойчивости; называют также «кредитный } \\
\text { рычаг» }\end{array}$ \\
\hline Рентабельность собственного капитала & $\begin{array}{l}\text { Главный показатель для стратегических инвесторов; } \\
\text { определяет эффективность использования капитала, } \\
\text { инвестированного собственниками предприятия }\end{array}$ \\
\hline Эффективность инноваций & $\begin{array}{l}\text { Характеризует степень внедрения прогрессивных тех- } \\
\text { нологий }\end{array}$ \\
\hline $\begin{array}{l}\text { Коэффициент освоения новой (инновационной) } \\
\text { продукции }\end{array}$ & $\begin{array}{l}\text { Характеризует способность предприятия к внедрению } \\
\text { инновационной или подвергшейся технологическим } \\
\text { изменениям продукции }\end{array}$ \\
\hline
\end{tabular}


созданию и росту стоимости предприятия.

Таким образом, современная концепция устойчивого развития промышленных предприятий ориентирована не только на обеспечение сиюминутных интересов бизнеса, но и на создание благоприятных условий для дальнейшего развития индустриального сектора России, так как ее реализация требует развития экономических аспектов деятельности путем реализация программ и проектов инновационной инду- стриализации.

Реиндустриализация как путь выхода из рецессии и база новой модели экономического роста - это мировой тренд, а экономическое управление устойчивым развитием промышленных предприятий играет решающую роль в ее реализации, так как учитывает особенности и технологические вызовы индустрии грядущих десятилетий, повышающих производительность труда и удешевляющих производство.

\section{Библиографический список}

1. Устойчивое развитие промышленного предприятия в условиях неоиндустриальной трансформации (Текст(: монография / (кол. авт.(; под науч. ред. Я.П. Силина; (отв. за вып. С.В. Орехова(; М-во образования и науки Рос. Федерации, УрО ВЭО России, Урал.гос. экон. ун-т.- Екатеринбург: Изд-во Урал.гос. экон. унта,2017.- 207 с.

2. О концепции перехода РФ к устойчивому развитию: указ Президента РФ от 15.08.1996 г. № 440.- Режим доступа: http://www.consultant.ru.

3. Бариленко, В.И. Основы бизнес-анализа: /В.И. Бариленко, В.В. Бердников, Р.П. Булыга [и др.]; под ред. В.И. Бариленко.- М.: КНОРУС, 2014-272 с.

4. Бодрунов, С.Д. Реиндустриализация российской экономики - возможности и ограничения / С.Д. Бодрунов // Абалкинские чтения.- С. 14-47.

5. Смирнова, Е.В. Экономическое управление сегментами бизнеса промышленных предприятий / Е.В. Смирнова, И.Ю. Цыганова // Экономические науки, 2018. - № 12 (169). - С. 22-29.

6. Тычинина, Н.А. Учетно-аналитическое обеспечение устойчивого развития предприятия: автореферат дис. ... кандидата экономических наук: 08.00.12 / Тычина Наталья Александровна; [Место защиты: Орлов. гос. техн. ун-т].- Орел, 2009.- 24 с. 